\title{
METODE TIGA LANGKAH: MENGAJAR BAHASA SUNDA DENGAN MATERI KAWIH ASUH BARUDAK
}

\author{
Dian Hendrayana \\ Departemen Pendidikan Bahasa Daerah FPBS UPI \\ Pos-el: dian.hendrayana@upi.edu
}

\begin{abstract}
Abstrak
Hampir di seluruh tingkatan (SD, SMP/MTs, SMA/SMK/MA) di Jawa Barat, para guru mata pelajaran Bahasa Sunda kerap mengeluhkan minimnya media pembelajaran dalam melaksanakan kegiatan belajar mengajar. Seperti diketahui, dalam Kurikulum 2013 perkakas yang disebut sebagai media pembelajaran sangat dibutuhkan demi membangun kegiatan belajar-mengajar yang kreatif, inovatif, dan menyenangkan. Media pembelajaran boleh jadi bisa berbentuk alat peraga, gambar-gambar, media audio, media audio-visual, pertunjukan, serta media lainnya yang mampu mebantu para guru terhadap kelancaran kegiatan belajarmengajar. Untuk memenuhi kebutuhan media pembelajaran bahasa Sunda tersebut, dalam empat tahun terakhir muncul salah satu bentuk media pembelajaran yang disebut 'Kawih Asuh Barudak'. Media ini berbentuk media audio yang berupa nyanyian berbahasa Sunda dengan peruntukan para siswa di tiga tingkatan. Atas rekomendasi Dinas Pendidikan Provinsi Jawa Barat, dalam satu setengah tahun terakhir, media pembelajaran 'Kawih Asuh Barudak' telah disosialisasikan melalui kegiatan pelatihan terhadap para guru di seluruh Jawa Barat, sehingga media pembelajaran ini hingga saat ini sudah mulai dimanfaatkan sebagai bahan penunjang dalam pembelajaran Bahasa Sunda.
\end{abstract}

Kata kunci: media pembelajaran, kawih asuh barudak, metode tiga langkah

\section{THREE STEPS METHOD: TEACHING SUNDANESE LANGUAGE WITH KAWIH ASUH BARUDAK MATERIALS}

\begin{abstract}
Almost in all school levels (SD, SMP/MTs, SMA/SMK/MA) in West Java, Sundanese language teachers often complain about the lack of teaching-learning media in carrying out teaching and learning activities. As it is known, in the Curriculum 2013 teaching-learning media is needed to build creative, innovative, and fun teaching and learning activities. Teachinglearning media can be designed in the form of teaching media, pictures, audio media, audiovisual media, performances, and other media that can help teachers to smooth teaching and learning activities. To meet the needs of teaching-learning Sundanese language media, in the last four years appeared one teaching-learning media called 'Kawih Asuh Barudak'. The form of this media is audio media in the form of Sundanese language song designed for students devided in three levels. On the recommendation of West Java Provincial Education Office, in the last one and a half years, the teaching-learning media 'Kawih Asuh Barudak' has been socialized through training activities for teachers throughout West Java, so this teachinglearning media has been utilized as a supporting material in Sundanese language learning Sunda.
\end{abstract}

Keywords: teaching-learning media, 'Kawih Asuh Barudak', three steps method 


\section{PENDAHULUAN}

Pembelajaran Bahasa Sunda seperti yang direkomendasikan melalui Kurikulum 2013 adalah penciptaan siswa yang aktif, terampil, dan kreatif dalam penguasaan bahasa Sunda. Adapun posisi guru ditempatkan sebagai ujungtombak dan pemberi stimulan (rangsangan, bahan dasar) yang selanjutnya akan dikembangkan dan dilaksanakan oleh para siswa dalam kehidupan sehari-hari. Pola inilah yang kemudian dianggap sebagai pola ideal dalam membentuk karakter para siswa menuju insan yang berahlak baik, berbudi pekerti tinggi, rajin, kreatif, dan pandai.

Untuk memenuhi pola pembelajaran seperti yang digariskan melalui Kurikulum 2013 ini maka sangat dibutuhkan perangkat pembelajaran sebagai penunjang dalam kegiatan belajar mengajar. Hal ini tiada lain sebagai upaya perubahan serta pengembangan strategi dan konsep dari pola ceramah seperti yang berlaku dalam kurikulum-kurikulum sebelumnya kepada pola pengembangan media pembelajaran yang secara efektif dan efisien mampu menunjang kelancaran pembelajaran serta mewujudkan cita-cita mulia demi menjadikan siswa sebagai insan yang berkarakter.

Dengan adanya penunjang pembelajaran yang dikemas sedemikian rupa sehingga mampu sedikit-sedikit mengubah metode kegiatan belajar-mengajar, maka pembentukan karakter yang berkualitas baik pada anak didik bukan tidak mungkin bisa terlaksanakan. Adapun harapan selanjutnya adalah mengantarkan perilaku anak didik ke arah yang berbudi pekerti tinggi dan berkarakter yang baik; para anak didik tidak lagi terlibat dengan aksi tawuran, akan berprilaku sopan dan santun, mengasihi terhadap sesama teman, atau menghormati guru dan orang tua. Karenanya, materi pembelajaran yang melibatkan aktivitas dan kreativitas anak didik -seperti yang dianjurkan Kurikulum 2013 sangatlah dibutuhkan.
Surat kabar Pikiran Rakyat edisi 2012 menurunkan laporannya bahwa saat ini anak-anak (di Indonesia) tidak memiliki lagu anak-anak. Karenanya anak-anak lebih banyak mengenal lagu peruntukan orang dewasa daripada lagu-lagu yang sesuai dengan kebutuhan psikologi usia di bawah 12 tahun. Maka akibatnya, seusia anak-anak itu lebih mengenal kondisi dan perilaku pergaulan kaum dewasa, ketimbang dunia mereka yang masih serba terbatas dalam koridor 'kesederhanaannya'.

Para ahli psikologi anak mengatakan, pada usia pertumbuhan, anak-anak memiliki kondisi tengah aktif-aktifnya merespon sesuatu yang dirasa baru kemudian disimpannya dalam memori kediriannya. Pada saatnya nanti, materi yang telah dikuasainya itu diaplikasikannya dalam kehidupan sehari-hari. Usia anak yang diibaratkan sebagai kertas putih nan bersih pada saatnya nanti akan diberikan berbagai aktivitas yang kelak akan dijadikan sebagai sumber memori yang setiap saat bisa diakses di saat dibutuhkan. Maka kertas putih tadi akan menjadi bernilai positif jika ditulisi serta dihias aktivitas-aktivitas yang positif pula.

Memang belum ada penelitian yang dengan tegas mengaitkan antara kurangnya lagu anak dengan kekerasan terhadap anak-anak. Namun, bukankah lagu anakanak memang penting untuk pertumbuhan anak-anak Indonesia? Tidak adanya lagu anak-anak itu sendiri adalah "kekerasan" terhadap anak-anak, karena memaksa mereka merekam lagu-lagu dewasa yang belum cocok mereka dengarkan (Hamzah pada layananpublik@kpi.go.id).

Hingga dekade 80-an, masayarakat Indonesia termasuk masyarakat Sunda masih memiliki materi lagu dengan peruntukan anak-anak. Bagi masyarakat Sunda, lagu-lagu seperti Kareta Mesin, Rasa Guligah, Baso Tahu, yang digubah oleh seniman Koko Koswara (Mang Koko) cukup populer di dunia anak-anak saat itu. Namun lagu yang diciptakan oleh Mang 
Koko dengan peruntukan anak-anak itu tidak lantas berlaku pula untuk para siswa yang notabene berada pada lingkungan pendidikan. Tidak semua lagu anak-anak bisa digunakan dan dimanfaatkan bagi kebutuhan pendidikan yang di dalamnya mengandung tujuan pembangunan karakter. Terlebih lagu-lagu yang pernah populer itu pada saat ini sudah tidak banyak terdengar lagi. Alhasil, anak-anak sekarang (terutama para siswa di lingkungan pendidikan) kesulitan untuk mendapatkan materi lagu peruntukan para siswa.

\section{METODE}

Dalam penelitian ini digunakan metode deskriptif, menguraikan tahapantahapan penelitian melalui kegiatan workshop. Workshop itu sendiri dilakukan terhadap para guru yang tergabung ke dalam MGMP (Musyawarah Guru Mata Pelajaran) Bahasa Sunda hampir di seluruh Jawa Barat dalam rentang waktu 20132014.

Kegiatan workshop dilaksanakan dengan berdasarkan 'Metode Tiga langkah' yang terdiri atas, Galindeng Maca, Galindeng Nutur, dan Galindeng Bisa. Galindeng Maca adalah metode yang melibatkan para peserta workshop untuk maca (membaca) teks hingga teks tersebut benar-benar terpahami; Galindeng Nutur adalah keterlibatan para peserta untuk nuturkeun (mengikuti) lagu yang dibunyikan melalui $\mathrm{CD}$ berdasarkan teks yang telah dipahaminya tadi, serta Galindeng Bisa adalah hal yang merupakan tujuan serta harapan akhir dari workshop agar para peserta bisa melagukan lagu Kawih Asuh Barudak sekaligus memahaminya secara kognitif, afektif, serta mampu menerapkannya dalam tataran psikomotor. Ketiga metode atau tahapan tadi akan dideskripsikan secara bertahap, guna memperoleh gambaran atas hasil dari kegiatan workshop tadi.

\section{HASIL DAN PEMBAHASAN}

Media pembelajaran adalah seperangkat alat atau media yang mampu menunjang materi pembelajaran. Dengan perangkat media pembelajaran tersebut, kegiatan belajar mengajar mengantar ke arah suasana kreatif, rekreatif, dan menyenangkan. Karenanya, sebagai metode alternatif, keberadaan media pembelajaran kerap dibutuhkan dalam kegiatan belajarmengajar.

Beberapa kurikulum terdahulu merekomendasikan bahwa kegiatan belajar-mengajar melalui metode ceramah merupakan metode yang cukup berhasil dan pas diberlakukan di sekolah. Namun seiring perkembangan teknologi dan perkembangan cara berfikir anak-anak, maka metode yang telah terbiasa diberlakukan dalam kurikulum terdahulu harus disesuaikan dengan perubahan zaman termasuk dengan perkembangan cara pola fikir yang berlaku pada psikologi anak didik.

Pengertian Media Pembelajaran Menurut Miarso (2004), "Media pembelajaran adalah segala sesuatu yang digunakan untuk menyalurkan pesan serta dapat merangsang pikiran, perasaan, perhatian, dan kemauan si belajar sehingga dapat mendorong terjadinya proses belajar". Peranan media pembelajaran tentulah sangat penting dalam menciptakan situasi belajar yang kondusif. Sehingga hasil belajarpun akan lebih maksmimal.

Menurut Heinich and Molenda (2002) terdapat enam jenis dasar dari media pembelajaran, yaitu: a. Teks. Merupakan elemen dasar dalam menyampaikan suatu informasi yang mempunyai berbagai jenis dan bentuk tulisan yang berupaya memberi daya tarik dalam penyampaian informasi. b. Media audio. Membantu menyampaikan maklumat dengan lebih berkesan dan membantu meningkatkan daya tarikan terhadap sesuatu persembahan. Jenis audio termasuk suara latar, musik, atau rekaman suara, dan 
lainnya. c. Media visual. Media yang dapat memberikan rangsangan-rangsangan visual seperti gambar/photo, sketsa, diagram, bagan, grafik, kartun, poster, papan buletin, dan lainnya. d. Media proyeksi gerak. Termasuk di dalamnya film gerak, film gelang, program TV, video kaset $(\mathrm{CD}$, VCD, atau DVD). e. Benda-benda tiruan/ miniatur. Termasuk di dalamnya bendabenda tiga dimensi yang dapat disentuh dan diraba oleh siswa. Media ini dibuat untuk mengatasi keterbatasan baik obyek maupun situasi sehingga proses pembelajaran tetap berjalan dengan baik. f. Manusia. Termasuk di dalamnya guru, siswa, atau pakar/ahli di bidang/materi tertentu.

Mendengarkan musik memiliki berapa manfaat salah satunya dapat meningkatkan fungsi otak kita bila dihubungkan dengan belajar bahasa Inggris. Melalui metode bernyanyi diharapkan mampu menarik minat anak untuk melakukan kegiatan pembelajaran Bahasa Sunda terutam penguasaan berbahasa, bersastra, serta budayanya dalam tataran dasar.

Mindradini (2012:12) mengatakan bahwa metode bernyanyi adalah suatu pendekatan pembelajaran yang secara nyata mampu membuat anak senang dan gembira, yang diarahkan pada suatu kondisi psikis untuk membangun jiwa yang bahagia, senang menikmati keindahan, mengembangkan rasa melalui bernyanyi yaitu ungkapan kata dan nada yang dirangkai hingga menjadi sebuah lagu, serta ritmik yang memperindah suasana belajar.

$$
\text { Materi 'Kawih Asuh Barudak' }
$$

(KAB) adalah kawih-kawih berbahasa Sunda yang dikemas sedemikian rupa untuk kebutuhan media pembelajaran bahasa Sunda di sekolah dan diberlakukan untuk jenjang SD (MI), SMP (MTs), dan SMA (MA/SMK). Pengemasan di sini termasuk pengemasan dalam sisi bahasa, musik, pembelajaran, serta kemasan dalam pertunjukannya.
Frase 'kawih asuh' dimaksudkan sebagai konsep materi lagu yang bisa dimanfaatkan untuk 'pengasuhan' yang melingkupi pembinaan, pendampingan, pelurusan, dari pihak pengajar kepada pihak yang menerima pelajaran dalam upaya pembentukan karakter siswa. Sejauh ini, lagu-lagu yang pernah diberikan kepada para siswa hanya dikemas sebatas pengayaan materi pembelajaran secara musikal. Adapun muatan pendidikan, dan terutama muatan pembentukan karakter, kerap terabaikan. Akibatnya, para siswa hanya memperoleh kekayaan lagu berbahasa Sunda tanpa menyentuh upaya aspek afektif atau aspek psikomotoriknya. Jikapun (pernah) ada lagulagu yang memiliki muatan pembentukan karakter, maka lagu tersebut sudah tidak lagi memenuhi standardisasi periode yang berlaku pada saat ini.

Kata 'barudak' dalam nomenklatur 'Kawih Asuh Barudak' merujuk pada anak didik di jenjang sekolah dasar (SD), sekolah menengah (baik tingkat SMP maupun SMA). Konsep 'barudak' adalah insan yang masih memiliki daya serap tinggi dan sangat aktif menerima berbagai hal yang masih terbilang baru. Karenanya, potensi yang berhubungan dengan daya serap ini perlu diberi asupan yang baik dan tepat, sesuai dengan kebutuhan kondisi jiwa dan psikologi yang dimilikinya (Erickson, 2015: 23).

Melihat kondisi kebutuhan usia 'barudak' ini, maka materi 'Kawih Asuh Barudak' disusun dan dikemas sesuai dengan kebutuhan yang terukur, dengan melihat kebutuhan 'kebahasaan', 'musikal', serta 'pengemasan tampilan' yang disesuaikan dengan takaran jiwa dan psikologi anak didik; mudah, ringan, riang, menyenangkan, memberi nasihat, belajar mencintai alam dan sesama.

Materi KAB disusun dalam bentuk compact disc (CD) di mana di dalamnya memuat 26 (dua puluh enam) lagu dengan komposisi musik serta komposisi bahasa yang disesuaikan dengan siswa sekolah 
tingkat dasar dan menengah. Ketigapuluh lagu tersebut dimuatkan ke dalam 4 (empat) CD di mana setiap CD dilengkapi pula dengan audio minus one (alunan instrumentalia tanpa lagu). Adapun kegunaan materi minus one tersebut dimaksudkan untuk melatih kemampuan para siswa dalam ngawih (menyanyi).

Secara keseluruhan, materi KAB akan terlihat pada tabel di bawah ini:

\section{1 (Album Cita-Cita)}

\begin{tabular}{llll}
\multicolumn{1}{c}{ No. } & \multicolumn{1}{c}{ Materi } & \multicolumn{1}{c}{ Keterangan } \\
\hline 1. & Cita-cita & $\begin{array}{l}\text { Lagu diciptakan Ubun R. Kubarsah } \\
(2012)\end{array}$ \\
\hline 2. & Basa Sunda & $\begin{array}{l}\text { Untuk setiap lagu dilengkapi dengan } \\
\text { musik minus one }\end{array}$ \\
\hline 3. Jalan Layang & & \\
\hline 4. & Pelesiran & Ciayumajakuning & \\
\hline 5. & Waditra &
\end{tabular}

\begin{tabular}{|c|c|c|}
\hline 7. & Jabodetabek & \multirow{6}{*}{$\begin{array}{l}\text { Dinyanyikan oleh: Rita Tila, Ujang } \\
\text { Supriatna, Tedi Sudiarto, dan Dini } \\
\text { Andrianti }\end{array}$} \\
\hline 8 & Katumbiri & \\
\hline 9 & Wisata Budaya & \\
\hline 10 & Hujan Turun & \\
\hline 11. & Du'a Indung Bapa & \\
\hline 12. & Internetan & \\
\hline \multicolumn{3}{|c|}{ CD 3 (Album Jasa Guru) } \\
\hline 13. & Jasa Guru & \multirow{7}{*}{$\begin{array}{ll}\text { - } & \text { Lagu diciptakan Gun Gunawi } \\
\text { - } & \text { Untuk setiap lagu dilengkapi dengan } \\
\text { musik minus one }\end{array}$} \\
\hline 14. & Budak Soleh & \\
\hline 15. & Wajib Belajar & \\
\hline 16. & Bon Bin & \\
\hline 17. & Urang Nabung & \\
\hline 18. & Priangan & \\
\hline 19. & Gedong Sate & \\
\hline \multicolumn{3}{|c|}{ CD 4 (Album Jasa Guru) } \\
\hline & Paturay & \multirow{7}{*}{$\begin{array}{l}\text { Dinyanyikan oleh: Lala Yuliara dan Nana } \\
\text { Suryana Fatah }\end{array}$} \\
\hline & Taman Mini & \\
\hline 22. & Nataan Pupuh & \\
\hline 23. & Pahlawan Bangsa & \\
\hline & Lalu Lintas & \\
\hline & Museum & \\
\hline 26. & Harak & \\
\hline
\end{tabular}

Musik yang diberlakukan dalam KAB dibagi menjadi dua macam, yakni musik dengan iringan musik barat (keyboard, biola) untuk siswa tingat SD, serta musik dengan iringan musik tardisional (kecapi,suling, kendang, dan biola) untuk siswa tingkat menengah yakni SMP/MTs. dan SMA/MA/SMAK. Hal ini dimaksudkan, untuk tingkat SD diberikan materi musik yang lebih umum dengan tingkat kesulitan yang paling rendah. Sedangkan untuk tingkat menengah diberikan materi yang memiliki tingkatan lebih khusus dan memiliki tingkat kesulitan yang rumit secara bertahap.

Metode pembelajaran dalam penelitian ini merupakan metode yang efektif dan efisien dalam mempraktekkan 
materi 'Kawih Asuh Barudak' sebagai media pembelajaran Bahasa Sunda. Artinya, melalui konsep ini para siswa dan para guru melaksanakan kegiatan belajar mengajar mata pelajaran Bahasa Sunda melalui kawih Sunda secara inovatif, kreatif, interaktif, dan rekreatif. Adapun dalam praktekknya, terdiri atas tiga langkah.

Langkah Pertama, metode galindeng maca, yakni para siswa mempelajari materi kebahasaan melalui pembacaan rumpaka (lirik) lagu. Dalam praktek workshop terhadap para guru yang tergabung kedalam MGMP Bahasa Sunda, materi teks rumpaka tersebut dibaca secara perlahan di dalam hati. Materi teks rumpaka tadi pun bisa dibacakan dengan gaya deklamasi serta pembacaan sajak. Dalam langkah ini, sesungguhnya para peserta workshop tengah mempelajari aspek 'kebahasaan' seputar fonologi, morfologi, sintaksis; atau juga materi sastra seputar sastra lama dan sastra baru. Dari kegiatan ini, para peserta workshop diupayakan mengerti dan menguasai aspek kebahasaan serta sastra yang tertera dan tersirat dalam lirik. Jika terdapat kata yang dianggap tidak dimengerti oleh peserta workshop, maka pihak pemberi materi berkewajiban menerangkannya sesuai kaidah kebahasaan dan kesastraan yang berlaku. Penguasaan terhadap aspek kebahasaan dan kesastraan ini dipandang sangat perlu dengan maksud agar dalam menyanyikan lirik tersebut, para peserta mampu berekspresi seperti yang 'diminta' oleh lirik lagu.

Sebagai contoh, lagu Du'a Indung Bapa (diambil dari album KAB, produksi Dasentra Bandung):

\section{DU'A INDUNG BAPA}

Gusti, pangeran abdi mugi asih ka pun biang sakumaha pun biang ka abdi miasih taya lirénna
Gusti, pangéran abdi

muga nyaah ka pun bapa

sakumaha pun bapa ka abdi

nu nyaah taya reureuhna

Asih indung asih bapa

teras nganteng teu laas ku mangsa

duh indung duh bapa

welas asih iklas taya pamrih

Du'a indung du'a bapa

tuduh jalan sangkan bener pinter

duh indung duh bapa

nungtun léngkah sangkan ulah salah

Berangkat dari lirik di atas, dalam prakteknya di dalam kelas nanti, para guru bisa mengajak dan melibatkan anak didik guna berdiskusi seputar materi kebahasaan, mulai dari masalah fonologi, morfologi, sintaksis, sinonim, antonim, hingga tataran kebahasaan yang lebih luas lagi. Atau bahkan mendiskusikan materi kesastraan seperti gaya bahasa, purwakanti, dan sebagainya. Termasuk di dalamnya upaya membangun karakter dengan mengajak para siswa agar senantiasa mendo'akan orang tua.

Kedua, metode Galindeng Nutur. Setelah para peserta workshop mengerti dan menguasai aspek kebahasaan, maka para peserta akan segera mendengarkan dan menyimak lagu berdasarkan lirik yang telah dipelajari sebelumnya (tentu saja dengan memutar $\mathrm{CD}$ materi $\mathrm{KAB}$ melalui $\mathrm{CD}$ player). Biarkanlah para peserta nuturkeun (turut menyanyi) seperti lantunan yang terdengar CD yang diputar. Metode Galindeng Nutur ini dimaksudkan agar para peserta terbiasa dengan turut menyanyikan lagu Sunda sebagai upaya membangun karakter melalui aspek cinta tanah air atau mencintai budayanya sendiri.

Untuk kebutuhan metode ini, lagulagu dalam KAB sengaja dibuat sedemikian rupa sehingga para peserta (pada prakteknya: para siswa) akan dengan mudah dan senang dalam menyerap nada- 
nada serta rangkaian melodi yang telah menjadi lagu secara utuh. Karenanya, melalui langkah kedua ini, para peserta akan secara intuitif dan alamiah mengikuti alunan lagu yang didengar dan disimaknya.

Lagu Du'a Indung Bapa sesungguhnya merupakan lagu Sunda yang berpangkal dari nada-nada pentatonik, namun memiliki kontur melodi yang mudah dan ringan, serta tidak memiliki motif-motif melodi yang rumit seperti pembubuhan cengkok, senggol, atau atribut melodi lainnya yang biasa berlaku pada lagu-lagu Sunda klasikal yang biasa didengar dari lagu-lagu gamelan.

Sebagaimana yang disampaikan Erickson dan Gardner, daya serap anakanak terhadap sesuatu yang baru akan lebih cepat meresap dibanding daya serap orang dewasa, maka sangat memungkinkan para anak didik pun akan mampu dengan cepat menyerap lagu kawih asih yang merupakan hal yang baru pula bagi para anak didik. Itu bisa tercapai jika materi yang berlaku pada KAB tadi merupakan materi yang mudah, ringan, inovatif, rekreatif, dan tentu saja menyenangkan.

Ketiga, metode Galindeng Bisa. Setelah membaca dan mencermati bunyi lirik lagu serta setelah mendengar, menyimak, serta nuturkeun (mengikuti) alunan melodi lagu secara utuh, maka pada langkah ketiga ini para peserta dengan sendirinya akan bisa dan mampu melantunkan lagu secara alamiah. Secara teknis, langkah ketiga ini, dalam prakteknya, para peserta akan melantunkan lagu atas iringan musik minus one dari lagu yang telah diberikan atau diajarkan oleh para pemateri melalui langkah pertama dan langkah kedua.

Materi KAB pernah disosialisasikan kepada para guru bahasa Sunda di Jawa Barat melalui Dinas Pendidikan Provinsi Jawa Barat pada tahun 2013-2014. Dari kegiatan tersebut, para guru cukup mengapresiasi materi $\mathrm{KAB}$ ini dalam memenuhi kegiatan belajar mengajar
(KBM). Selain dirasakan cukup mudah, melalui materi $\mathrm{KAB}$ ini, cara mengajar bahasa Sunda kepada para siswa menjadi lebih menarik dan menyenangkan.

Bahkan untuk beberapa daerah seperti Kota bandung, Kota Depok, Kota Sukabumi, Kota Bogor telah menyelenggarakan pasanggiri (lomba) materi KAB. Yang menarik, di Kota Depok, di mana para siswanya lebih banyak bukan berdarah orang Sunda, materi KAB ini banyak diminati dan disenangi.

\section{SIMPULAN}

Ketiga langkah dalam Metode Tiga Langkah, dalam prakteknya membutuhkan 'pengasuhan' dari pengajar (guru). Karenanya, metode 'tiga langkah' ini akan menjadi pola pembelajaran yang ideal dengan melibatkan kerja guru serta pemusatan konsentrasi para siswa. Dengan demikian, 'kedekatan' antara siswa dan guru secara psikologis serta merta akan terbangun. Dan jika sudah terbangun seperti itu, maka sentuhan-sentuhan moral demi pembangunan karakter bangsa akan relatif mudah bisa diwujudkan.

\section{PUSTAKA RUJUKAN}

Erickson, dan Gardner. 2015. Teori Perkembangan Anak. Internet

Gunawi, Gun. 2-12. Jasa Guru: Album Kawih Asuh Barudak. Bandung: Dasentra (Daya Seni Tradisi Sunda)

Hamzah. layananpublik@kpi.go.id diunduh tanggal 2 Juni 2017.

Heinich, R, Molenda, M. 2002. Intructional Media and Technology for Learning, $7^{\text {th }}$ Edition. New Jersey: Prentice Hall, inc.

Kubarsah, Ubun. 2012. Cita-cita: Album Kawih Asuh Barudak. Bandung: Dasentra (Daya Seni Tradisi Sunda)

Mindradini, Listiyorini Etta. 2012. Penggunaan Metode Bernyanyi untuk Meningkatkan Pembiasaan Dalam Pembentukan Nilai - nilai Moral pada Anak Kelompok B di TK 
Dharmahusada Surabaya. Skripsi Tidak diterbitkan. Jurusan Pendidikan Guru Pendidikan Anak Usia

Miranti, Ira, dkk. Faktor Jurnal Ilmiah Kependidikan Vol. II No. 2 Juli 2015.

\section{UCAPAN TERIMA KASIH}

Terima kasih penulis sampaikan kepada penyunting Jurnal Lokabasa atas dimuatnya tulisan ini. 